\title{
Synthesis of silver nanoparticles in NMMO and their in situ doping into cellulose fibers
}

\author{
Olga Rac-Rumijowska ${ }^{(10} \cdot$ Marta Fiedot • Iwona Karbownik • \\ Patrycja Suchorska-Woźniak • Helena Teterycz
}

Received: 21 July 2016/Accepted: 15 December 2016/Published online: 10 January 2017

(C) The Author(s) 2017. This article is published with open access at Springerlink.com

\begin{abstract}
We present a method for synthesis of silver nanoparticles in $\mathrm{N}$-methylmorpholine $\mathrm{N}$-oxide (NMMO) and the associated mechanism, as well as their use for in situ volume modification of cellulose fibers. The synthesized particles had diameter of about $4 \mathrm{~nm}$, and their colloid solution was stable for 1 year. The nanoparticles were stabilized using polyethylenimine, which apart from preventing nanoparticle agglomeration, also accelerated $\mathrm{Ag}^{+}$ion reduction and prevented NMMO degradation. A mechanism for the nanoparticle synthesis is suggested based on the electrochemical potentials of all ions in solution, with perhydroxyl ions resulting from NMMO reducing the silver ions. We also created nanocomposites from fibers and silver nanoparticles, in which the latter showed very good dispersion in the fiber volume. Such spun fibers showed improved mechanical parameters in comparison with unmodified fibers.
\end{abstract}

O. Rac-Rumijowska $(\bowtie) \cdot$ M. Fiedot .

P. Suchorska-Woźniak · H. Teterycz

Faculty of Microsystem Electronics and Photonics,

Wrocław University of Technology, Janiszewskiego

11/17, 50-372 Wrocław, Poland

e-mail: olga.rac@pwr.edu.pl

I. Karbownik

Faculty of Material Technologies and Textile Design,

Technical University of Łódź, Żeromskiego 116,

90-924 Łódź, Poland
Keywords Cellulose fibers $\cdot N$-Methylmorpholine $\mathrm{N}$-oxide $\cdot$ Silver nanoparticles $\cdot$ Polyethylenimine

\section{Introduction}

Recently, increasing attention has been paid to manufacture of modern functional fabrics offering antibacterial properties (Wendler et al. 2007; Emam and Zahran 2015), high electrical conductance (Zabetakis et al. 2005), or ultraviolet (UV) protection (Emam et al. 2016). To create such textile fabrics with unusual properties or "intelligent" textile fabrics for use in textronics or medicine, it is essential to develop new methods for modification of different polymeric fibers. Due to its ready availability and wide range of applications, cellulose is often used for production of nanocomposite fibers (Siro and Plackett 2010).

To endow fabrics with new properties, they can be doped with metal or inorganic compound nanoparticles, carbon nanotubes, or graphene (Kim et al. 2011). Doping of polymeric fibers is, however, extremely difficult, due to their properties and the specifics of the synthesis of such materials. The requirement that modified fabrics must not have mechanical properties inferior to those of standard fabrics further increases this difficulty.

Modern cellulose fibers of Lyocell type are spun from spinning solution containing cellulose dissolved in aqueous solution of NMMO. Volume modification 
of such fibers by nanoparticles requires their addition to the spinning solution, in colloid or dry powder form (Wendler et al. 2007).

Such addition of colloidal nanoparticles into the spinning solution requires large amounts of water and appropriate substances to stabilize their volume and shape and prevent their agglomeration. This alters the rheological properties of the spinning solution, limiting or even preventing the fiber spinning process. Too high water concentrations in the system prevent cellulose dissolution. A lengthy water removal process is then required, leading to cellulose degradation in the spinning solution.

Application of dry nanopowder poses a significant challenge regarding homogeneous dispersion in the spinning solution, which is a very difficult and energyconsuming process. For the aforementioned reasons, cellulose fibers modified using such methods show poorer mechanical strength.

The best solution to such problems occurring during volume modification of fibers is use of an in situ method of nanoparticle synthesis during preparation of the spinning solution, permanently fixing the added material to the fibers.

However, such nanoparticle synthesis in the highviscosity spinning solution is complicated. Firstly, it requires optimization of the nanoparticle synthesis for the specific solvent used in the spinning solution. The aim of the present research is to analyze the processes occurring during nanoparticle synthesis in solution of $\mathrm{N}$ methylmorpholine $N$-oxide (NMMO). NMMO aqueous solution (50\%) is typically applied to dissolve cellulose during Lyocell fiber production (Rosenau et al. 2001). In the present research, silver was chosen for volume modification of cellulose fibers, as it is a material commonly used in synthesis of polymeric conductive layers in microelectronics (Allen et al. 2011). Literature provides many examples of the combination of silver micro- and nanoparticles with cellulose surface (Emam et al. 2013) or incorporation of silver nanoparticles (AgNPs) in viscose fibers (Emam et al. 2014).

There are many methods for synthesis of silver nanoparticles, each resulting in particles with different characteristics, e.g., size distribution, diameter, shape, stability, or amounts of contamination. Silver nanoparticles can be synthesized in various solutions, e.g., alginate (Zahran et al. 2014), among which aqueous solutions are most frequently reported (Zhang et al. 2007). Silver nanoparticles are usually created by reduction of silver nitrate using ascorbic acid; other commonly used reduction agents include ethanol, sodium citrate, ethylene glycol, and sodium borohydride. The reduction of silver ions is also induced by UV radiation (Sato-Berru et al. 2009; Courrol et al. 2007) or by polysaccharides, including cellulose (Emam and Ahmed (2016); Emam et al. 2016). However, there are no publications on in situ synthesis of silver nanoparticles in the presence of a stabilizer in spinning solution for Lyocell fiber production. Silver nanoparticle synthesis is typically conducted in the presence of stabilizers which not only prevent their agglomeration but also determine their size and shape. In some cases, the same substance acts as both stabilizing and reducing agent (Starch et al. 2014). In the case of nanoparticle synthesis in spinning solution, one should bear in mind that the chosen stabilizer must not negatively affect the fiber creation process. Polyethylenimine (PEI), used here during volume modification of cellulose fibers, is a good stabilizer of nanoparticle size and shape (Lee et al. 2011). Silver nanoparticles stabilized using this polymer have been synthesized during the preparation of cellulose spinning solution (Karbownik et al. 2012). However, a similar method for synthesis of spun cellulose fibers doped with silver nanoparticles (Smiechowicz et al. 2011) did not use a stabilizer; rather, nanoparticle synthesis occurred prior to their introduction into the spinning solution, and the resulting nanoparticles were polydisperse. In addition, due to the lack of stabilizer, their concentration in the spinning solution was not high. Hence, this method is not suitable for production of spun fibers with high electrical conductance or mechanical strength. However, the success of this method requires an explanation of the mechanism of nanoparticle creation in solution of $\mathrm{N}$-methylmorpholine $\mathrm{N}$-oxide. Furthermore, it is also necessary to discuss the influence of stabilizing polymers and other process parameters on the kinetics of such silver nanoparticle synthesis methods in strongly oxidizing conditions, i.e., $50 \%$ solution of NMMO.

We present herein the results of a study aiming to explain the processes occurring during such synthesis of nanoparticles in NMMO. We also suggest the mechanism of silver nanoparticles synthesis in $50 \%$ aqueous solution of NMMO in presence of polyethylenimine as stabilizer. On the basis of the results obtained for synthesis of silver nanoparticles in 
NMMO, which is a cellulose solvent, we also present a new method for volume modification of cellulose fibers using such silver nanoparticles, synthesized in situ in the spinning solution.

\section{Experimental}

\section{Materials}

Nanoparticles were synthesized in $50 \%$ aqueous solution of $\mathrm{N}$-methylmorpholine $\mathrm{N}$-oxide (NMMO) from Hunstman Holland BV. The following polymers were used as stabilizing additives:

- Polyethylenimine (PEI) with average molecular weight of $2 \mathrm{kDa}, 750 \mathrm{kDa}$ and with high molecular weight, from Sigma-Aldrich (Germany) (Fig. 1a)

- Polyvinylpyrrolidone (PVP) with average molecular weight of 8 or $58 \mathrm{kDa}$, from Sigma-Aldrich (Germany) (Fig. 1b)

- Polyethylene glycol (PEG) with average molecular weight of $3 \mathrm{kDa}$, from $\mathrm{POCH}$ (Poland) (Fig. 1c)

Each polymer was prepared in aqueous solution at concentration of 43 (PEI), 111 (PVP), and $44 \mathrm{~g} / \mathrm{L}$ (PEG), corresponding to solution concentration of $1 \mathrm{~mol} / \mathrm{L}$ after conversion of mer per liter to molecular weight. This definition of polymer concentration is commonly used and greatly facilitates calculations of added substrate amounts. These polymers are known to be among the most effective and commonly used stabilizers to prevent agglomeration of silver nanoparticles.

Silver nitrate $\left(\mathrm{AgNO}_{3}, 99.999 \%\right.$ purity; $\mathrm{POCH}$, Poland) at concentration of $0.04 \mathrm{~mol} / \mathrm{dm}^{3}$ was used as $\mathrm{Ag}^{+}$ion precursor. Cellulose pulp containing $98 \mathrm{wt} \%$ a-cellulose with average degree of polymerization (DP) of about 1250 and NMMO as $50 \%$ aqueous solution (from Huntsman Holland BV, The Netherlands) were used for preparation of spinning dope. Propyl ester of gallic acid (Tenox PG) from Aldrich (Gillingham, Dorset, UK) was applied as antioxidant (molecular weight stabilizer). All the above-mentioned chemicals were used as received without further purification.

Synthesis of silver nanoparticles

Synthesis of nanoparticles was conducted in constant volume of $40 \mathrm{~mL}$ by adding substrates consecutively to NMMO solution, stirred using a magnetic stirrer. Firstly, the stabilizing polymer was added to the NMMO solution, then after thorough stirring, the silver ion precursor. To prevent electromagnetic radiation from affecting the kinetics of silver ion reduction, the bottles containing silver colloids were protected by aluminium foil prior to the start of synthesis.

The basic sample with silver ion concentration of $250 \mathrm{ppm}$ contained $2.7 \mathrm{mmol} / \mathrm{L} \quad \mathrm{AgNO}_{3}$ and $1.8 \mathrm{mmol} / \mathrm{L}$ polyethylenimine $\left(M_{\mathrm{w}}=2 \mathrm{kDa}\right)$ in $50 \%$ aqueous solution of NMMO. In subsequent

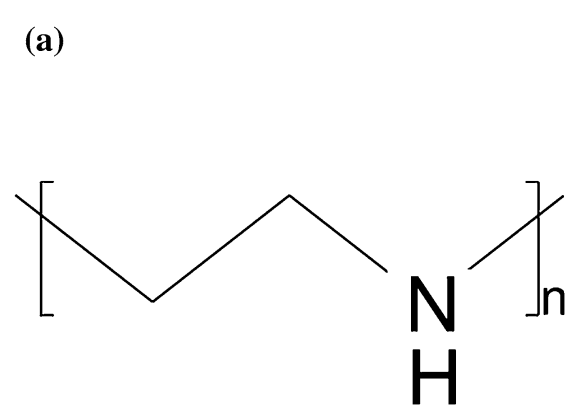

(b)

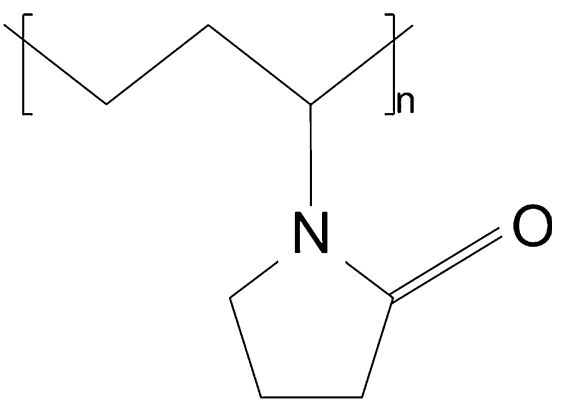

(c)

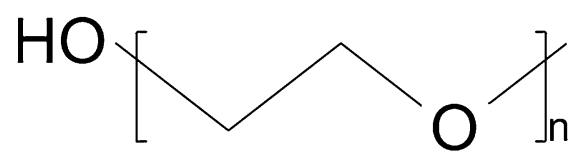

Fig. 1 Chemical structure of applied stabilizers: a polyethylenimine, b polyvinylpyrrolidone, and c polyethylene glycol 
trials, either the stabilizer was changed or the synthesis was conducted without stabilizer.

Spinning of fibers

Silver nanoparticles were synthesized in situ in the spinning solution. An amount of silver nitrate was added to obtain cellulose fibers containing $5000 \mathrm{ppm}$ silver. Fibers were spun from $8 \%$ solution of cellulose in NMMO. In the first stage, cellulose was soaked with aqueous solution of $\mathrm{N}$-methylmorpholine $\mathrm{N}$-oxide (NMMO). After initial mixing of fragmented cellulose with NMMO, the mixture was transferred to a kneader. Tenox PG was added to the system at $1 \%$ by weight, $\mathrm{AnNO}_{3}$ at $0.5 \%$ by weight, and PEI at $2.1 \%$ by weight. Cellulose solutions in NMMO with additives were obtained using a high-efficiency laboratory-scale IKAVISC kneader (type MKD 0.6-H60) supplied by IKA-Analysentechnik GmbH (Heitersheim, Germany). Cellulose dissolution was carried out at elevated temperature of $114{ }^{\circ} \mathrm{C}$ and reduced pressure of $240 \mathrm{hPa}$. Synthesis of silver nanoparticles took place at the same time, directly in the spinning solution. The dissolution process occurs most efficiently when the content of water in the $\mathrm{H}_{2} \mathrm{O}-\mathrm{NMMO}$ system does not exceed $13.5 \%$, which corresponds to the amount of monohydrate in the NMMO system. This value diverges from that presented in the NMMO-cellulose-water graph, due to the fact that the spinning mass contains silver nanoparticles that affect the rheological properties of the solution. We determined this value experimentally by spinning many fiber/nanoparticle admixtures. We have investigated in situ addition of silver nanoparticles to polyacrylonitrile fibers, revealing that the nanoparticles dilute the spinning solution (Karbownik et al. 2015). High temperature and the alkalinity of NMMO may cause cellulose degradation. This can be prevented by using an antioxidant stabilizer such as propyl 3,4,5-trihydroxybenzoate (Tenox PG) at $1 \%$ of cellulose weight. This ensured that the degree of polymerization (DP) of the cellulose did not drop below 500 .

The dissolution process was carried out until the appropriate temperature and solution composition were attained, i.e., when the appropriate amount of water was present in the mixture.

Fibers were formed by the dry-wet method using a laboratory-scale piston-spinning device through a spinneret with 18 orifices of $0.4 \mathrm{~mm}$ diameter. Fibers were extruded at speed of $30 \mathrm{~m} / \mathrm{min}$ across a $15-\mathrm{cm}$ air gap then exposed to two baths. In the first bath, fast cooling of the fiber to temperature of $20^{\circ} \mathrm{C}$ and coagulation took place, thus the fibers retained their anisotropic properties. The fibers were then exposed to a warmer $\left(70{ }^{\circ} \mathrm{C}\right)$ plasticizing bath to ensure appropriate flexibility. This elevated temperature reduced defects and stress in the fibers.

Characterization of silver nanoparticles and nanocomposite fibers

\section{UV-Vis spectroscopy}

Spectroscopic studies were performed at $23{ }^{\circ} \mathrm{C}$ in quartz trays using an Evolution $201 \mathrm{UV}-\mathrm{Vis}$ spectrophotometer from Thermo Scientific Company.

\section{Dynamic light scattering (DLS)}

The size distribution of the formed nanoparticles was determined by the dynamic light scattering (DLS) method using a Nicomp 380ZLS (Particle Sizing Systems, USA) including a laser with wavelength of $532 \mathrm{~nm}$ and power of $50 \mathrm{~mW}$. The frequency of the photons measured by the autocorrelator was fixed at about $200 \mathrm{kHz}$, with time of $3 \mathrm{~min}$ for each measurement. A polymethylmethacrylate (PMMA) tray with dimensions of $40 \times 10 \times 10 \mathrm{~mm}^{3}$ was used for the measurements. The hydrodynamic diameter was calculated using the Stokes-Einstein equation, assuming measurement temperature of $298 \mathrm{~K}$ and viscosity of the continuous phase (water) of $0.891 \mathrm{mPa}$.

\section{High-resolution transmission electron microscopy (HRTEM)}

Microstructural studies of the silver particles were conducted using an FEI Tecnai G2 20 X-TWIN equipped with an energy-dispersive anlaysis of X-rays (EDAX) microanalyzer.

Analysis of the elemental composition of the prepared fibers was performed by scanning electron microscopy (SEM) (LEO 435 VP, Zeiss + Leica), equipped with an energy-dispersive X-ray spectroscopy (EDS) microanalysis system from Rontec $\mathrm{GmbH}$. 
The chemical structure of the samples was examined by Fourier-transform infrared (FTIR) spectroscopy using a Thermo Scientific Nicolet 380 spectrometer. Spectra were recorded in the range of 60-4000 $\mathrm{cm}^{-1}$ at resolution of $4 \mathrm{~cm}^{-1}$.

The strength tests carried out on the fibers included measurements of breaking force at constant speed (according to PN-85/P-04761/04), static tensile index (according to PN-EN ISO 5079), and breaking strength and elongation of individual filaments. The linear density was determined by the method of sections, in accordance with PN-89/P-04653. Samples were conditioned at $60 \%$ relative humidity and $T=293 \mathrm{~K}$ during $24 \mathrm{~h}$. Strength calculations were based on the above standards. The mechanical properties of the cellulose fibers were checked using a tensile testing machine (type Z2.5/TN1S from Zwick GmbH, Ulm, Germany). The computer was equipped with a device to automate the entire process and allow analysis of the results. Measurements were performed at constant elongation rate of $5 \mathrm{~mm} / \mathrm{min}$ on samples with length of $20 \mathrm{~mm}$. The average time to break under tension was $20 \pm 3 \mathrm{~s}$. Each strength test was performed 50 times, and average results are given.

\section{Results and discussion}

Nanoparticle colloid test results

\section{Basic sample test results}

A colloid solution was created by reduction of silver ions in the basic sample containing $50 \%$ aqueous solution of $\mathrm{NMMO}, \mathrm{AgNO}_{3}$ at concentration of $2.7 \mathrm{mmol} / \mathrm{L}$, and polyethylenimine $\left(M_{\mathrm{w}}=2 \mathrm{kDa}\right)$ at $8.1 \mathrm{mmol} / \mathrm{L}$. In the UV-Vis spectrum of the colloid solution, a characteristic peak was observed at wavelength of $420 \mathrm{~nm}$, indicating presence of silver nanoparticles (Fig. 2a).

According to the DLS results, the average size of the silver nanoparticles synthesized in the basic solution was about $4 \mathrm{~nm}$ (Fig. 2b).

\section{Effect of polymeric stabilizers}

During chemical synthesis of nanoparticles of various materials, including silver, stabilizers are used to prevent agglomeration, also affecting the size and
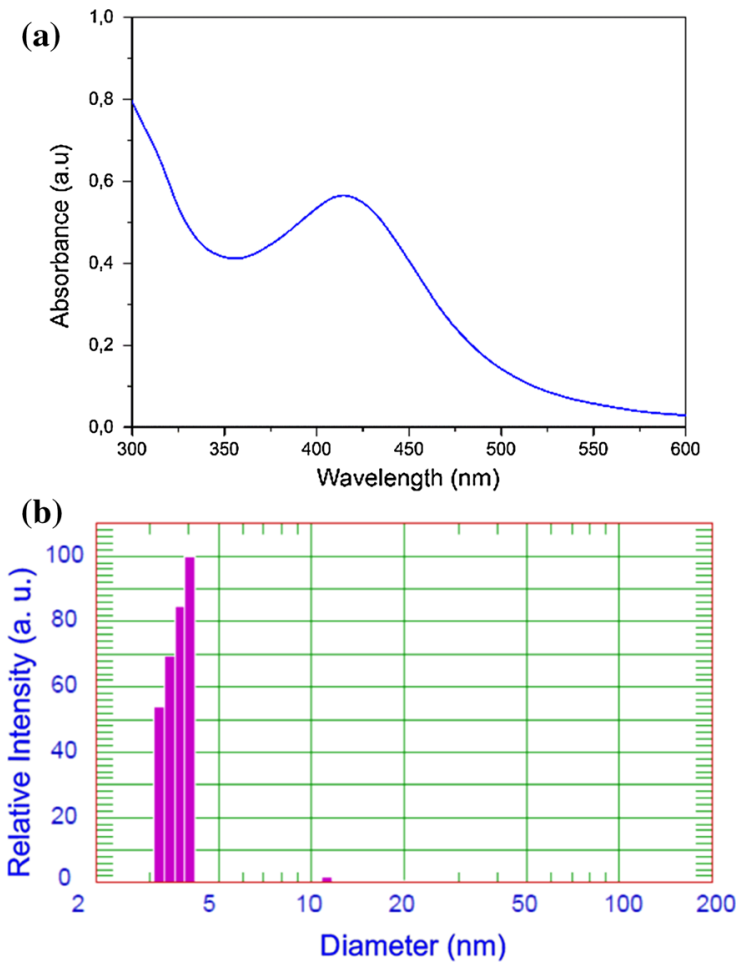

Fig. 2 Results of measurements on the basic sample: a UV-Vis spectrum, b distribution of silver nanoparticle diameter, as determined by DLS

shape of the resulting nanoparticles. During the synthesis of silver nanoparticles in aqueous solution, three different polymers, i.e., polyvinylpyrrolidone (PVP), polyethylene glycol (PEG), and polyethylenimine (PEI), were used as stabilizers. The aim of the first stage of the tests was to determine the effect of the kind of stabilizer and its molecular weight on the reduction process. The peak typical for silver was only observed when polyethylenimine was used as stabilizing agent (Fig. 3), occurring between 400 and $450 \mathrm{~nm}$ depending on the mean molecular weight of the PEI. According to Mie theory (1908), such a shift in the absorption signal is due to a change in the size and/or shape of the nanoparticles. In the case of highmolecular-weight polyethylenimine, the peak was very broad, revealing that the synthesized particles had large diameter. Meanwhile, in the spectra of the colloids stabilized using polyvinylpyrrolidone or polyethylene glycol, regardless of their molecular weight, no characteristic peak of silver nanoparticles was observed. In the presence of these polymers, large silver particles formed and quickly settled to the bottom of the measuring cuvette. 


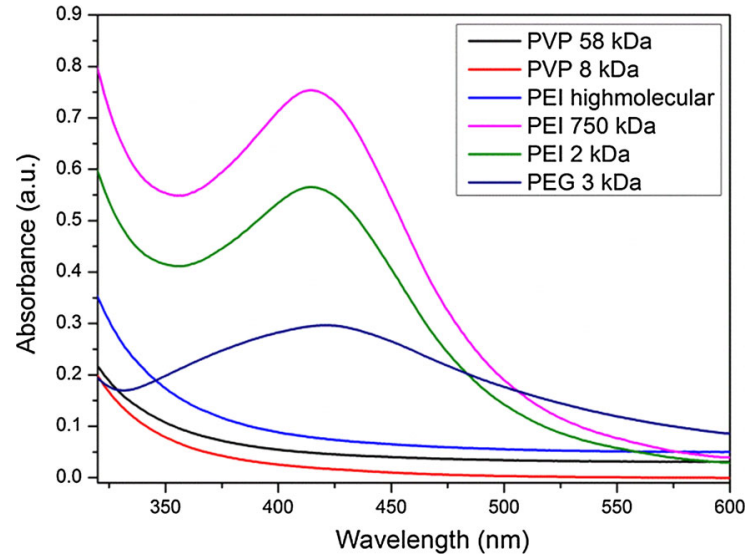

Fig. 3 UV-Vis spectra of silver colloids synthesized in solutions containing different polymers as stabilizer

DLS measurements of the average size of the synthesized particles confirmed these observations and UV-Vis test results. Monodisperse silver nanoparticles were only synthesized in presence of polyethylenimine as stabilizer (Fig. 4), their size depending on the average molecular weight of the
PEI. The particles synthesized in presence of PEI with average molecular weight of $M_{\mathrm{w}}=750 \mathrm{kDa}$ or $M_{\mathrm{w}}=2 \mathrm{kDa}$ measured 4 and $11 \mathrm{~nm}$, respectively, while large particles exceeding $200 \mathrm{~nm}$ were synthesized in presence of high-molecular-weight branched polyethylenimine.

It is suggested that these changes in the resulting silver nanoparticles are related to the length of the polymeric chain, as effective nanoparticle stabilization is only achieved by polymers of appropriate length and macromolecular structure (Mikami et al. 2011). One end of the polymer binds with the nanoparticle surface, whereas the remaining part forms a loose layer around the nanoparticle. A double polymer layer is thereby formed, consisting of polymer functional groups chemically bound to the nanoparticle surface and polymer chains located on the outer layer. When this polymer layer has appropriate thickness, it can effectively protect the particles from agglomeration (Fig. 5a, b). However, polymers that are too long may become excessively entangled in solution, in turn resulting in gathering of particles and their agglomeration (Fig. 5c).
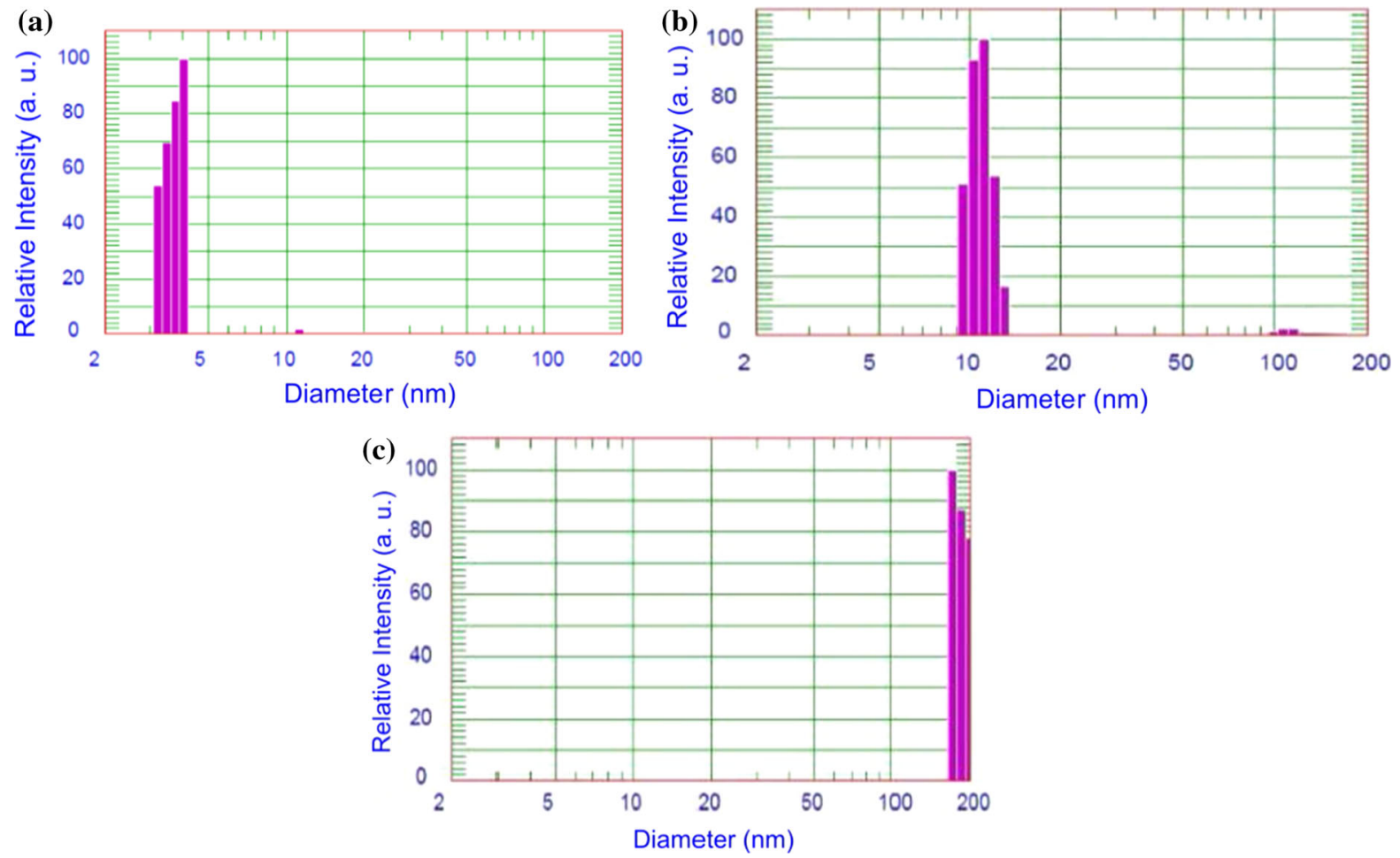

Fig. 4 Diameter distributions obtained by the DLS method for silver nanoparticles stabilized using polyethylenimine with a $750 \mathrm{kDa}$, b $2 \mathrm{kDa}$, and c high molecular weight 

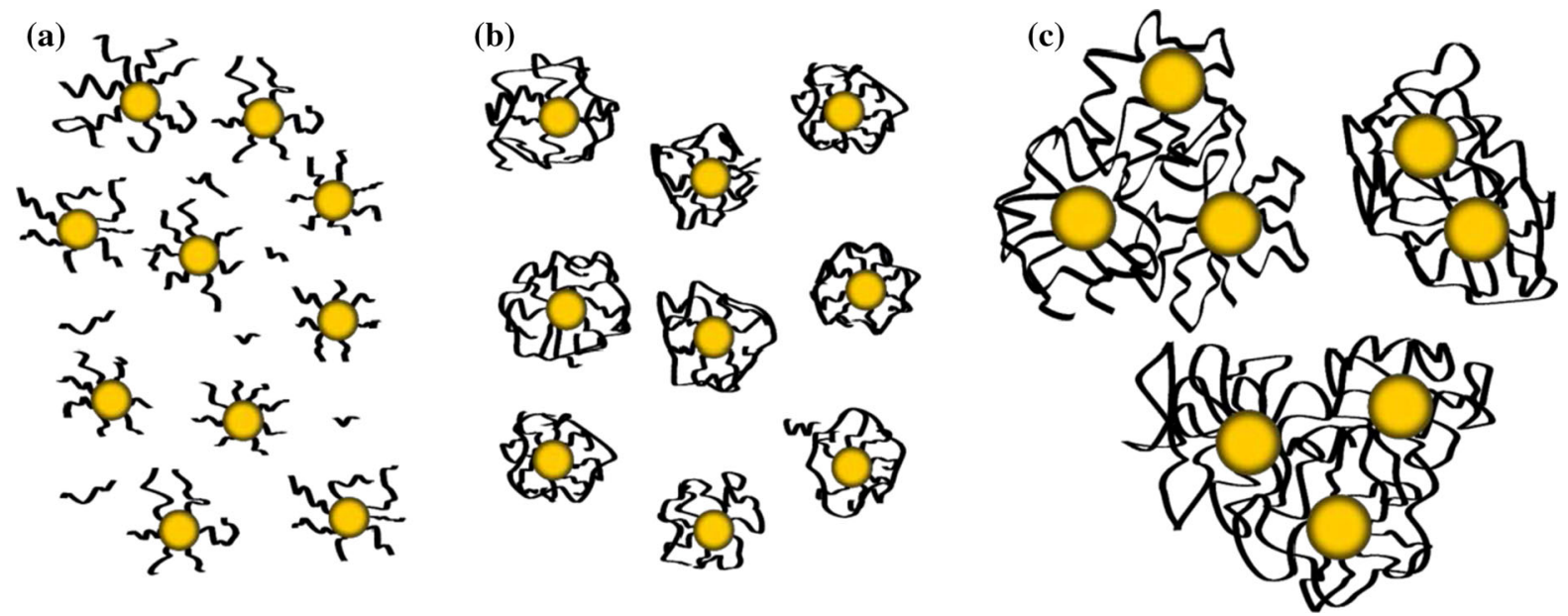

Fig. 5 Stabilization of silver nanoparticles depending on the length of PEI chain: a low, b medium, and $\mathbf{c}$ high molecular weight

On the basis of these tests, it was concluded that silver nanoparticles were only created in solution of NMMO with polyethylenimine as stabilizer. For this reason, further tests were conducted using PEI with $M_{\mathrm{w}}=2 \mathrm{kDa}$.

The presence of stabilizer on the nanoparticle surface was confirmed by HRTEM observations (Fig. 6), which clearly showed that silver nanoparticles synthesized in NMMO solution lay within polymeric micelles, protecting them from further growth or agglomeration.

\section{Effect of temperature on particle size}

Spinning solution for cellulose fiber production is prepared at elevated temperature. Therefore, the

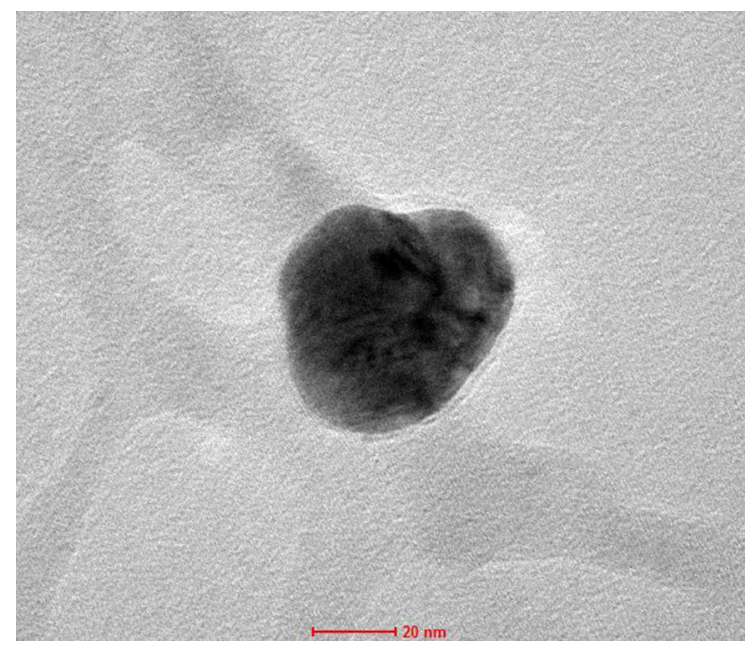

Fig. 6 HRTEM image of silver nanoparticle stabilized with polyethylenimine influence of temperature on the synthesis of silver nanoparticles was studied. During these tests, reduction of silver ions was conducted at ambient temperature as well as when heating the sample at $70{ }^{\circ} \mathrm{C}$ for $60 \mathrm{~min}$. In both cases, the characteristic peak appeared in the UV-Vis spectrum after $24 \mathrm{~h}$ (Fig. 7a). Monodisperse colloid solution containing nanoparticles with mean size of $5 \mathrm{~nm}$ was also created at the elevated temperature (Fig. 7b).

At ambient temperature, larger nanoparticles (approximately $8 \mathrm{~nm}$ ) were formed (Fig. 7). The smaller size of the nanoparticles obtained at higher temperature may be due to accelerated nucleation and creation of the nanoparticles themselves. As a result, more smaller nanoparticles were created in the solution compared with synthesis at ambient temperature.

\section{Effect of PEI on silver nanoparticle synthesis}

The first aim here was to determine whether it is necessary to apply polyethylenimine in the synthesis. UV-Vis results showed that silver nanoparticles were created both in presence of and without stabilizing polymer. Reduction of silver ions occurred in both cases. However, the synthesis of nanoparticles was much slower in the solution without stabilizer, and the synthesized nanoparticles agglomerated quickly (Fig. 8a). Therefore, we conclude that polyethylenimine does not trigger silver ion reduction but acts as an effective stabilizer of the nanoparticle size. HRTEM results showed that nanoparticles of similar size were created in both presence and absence of 

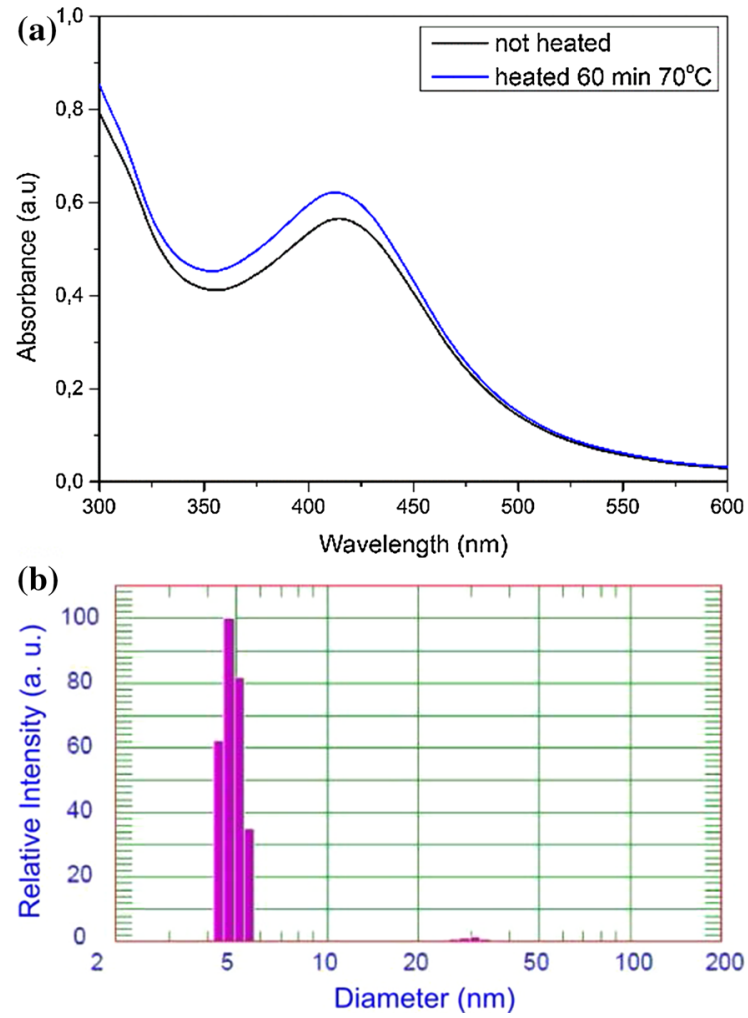

Fig. 7 Measurements on silver colloids stabilized using polyethylenimine with $M_{\mathrm{w}}=2 \mathrm{kDa}$ and heated at $70{ }^{\circ} \mathrm{C}$ for 60 min: a UV-Vis spectrum, b DLS test results

polyethylenimine as stabilizer. However, the nanoparticles synthesized in presence of polyethylenimine did not exhibit agglomeration (Fig. 8b), in contrast to the nanoparticles synthesized without stabilizer (Fig. 8c).

The observed agglomeration of nanoparticles synthesized without stabilizing polymer is typical of nanomaterials. Due to their high surface energy, they have a tendency to agglomerate. For this reason, different stabilizing substances are commonly used in their synthesis (Kholoud et al. 2010).

\section{Development of nanoparticle synthesis}

The nanoparticle synthesis process was analyzed by observing the change in the absorption of the solution over time. At each time point, $0.5 \mathrm{~mL}$ of reaction mixture was diluted with deionized water to volume of $4 \mathrm{~mL}$. The reaction was conducted at ambient temperature. Two absorption peaks were observed in the $\mathrm{UV}-\mathrm{V}$ is spectrum of colloids synthesized in presence of PEI (Fig. 9). The first, much weaker peak occurred at wavelength of $320 \mathrm{~nm}$ (Fig. 9a), while the other, much more intense peak occurred at wavelength of about $420 \mathrm{~nm}$ (Fig. 9b). The peak at $320 \mathrm{~nm}$ was observed within the first few dozen minutes of reduction. It then disappeared, and the other peak at wavelength of about $420 \mathrm{~nm}$ appeared. The peak intensity increased with the duration of the synthesis. In presence of PEI, maximum absorption was reached within $24 \mathrm{~h}$.

Silver ion reduction also occurred in the case of synthesis in NMMO solution without stabilizer (PEI), but much more slowly. The peak typical of $\mathrm{Ag}$ nanoparticles was not observed in the spectrum after $24 \mathrm{~h}$ (Fig. 9c). Only after $48 \mathrm{~h}$ did this peak start to appear, and its intensity was still increasing after 100 h. These results confirm that PEI acts to stabilize the nanoparticles and accelerates the reaction leading to their creation.

During reaction, silver ions are reduced to their metallic form $\mathrm{Ag}^{0}$ (1); silver atoms then bond with silver ions to create dimer cations $\mathrm{Ag}_{2}^{+}$(2), which may also bond in pairs to create tetracations $\mathrm{Ag}_{4}^{2+}$ (3). Further reactions of ions, atoms, dimer cations, and tetracations lead to creation of metallic silver nanoparticles.

$\mathrm{Ag}^{+}+1 \mathrm{e}^{-} \rightarrow \mathrm{Ag}^{0}$

$\mathrm{Ag}^{0}+\mathrm{Ag}^{+} \rightarrow \mathrm{Ag}_{2}^{+}$

$2 \mathrm{Ag}_{2}^{+} \rightarrow \mathrm{Ag}_{4}^{2+}$.

The two peaks observed in the UV-Vis spectra (Fig. 9) are connected with the presence of silver in different forms. The first peak at wavelength of $310 \mathrm{~nm}$ is connected to presence of di- and tetracations or small nonmetallic clusters $\left(\mathrm{Ag}_{n}\right)$. These molecules are created at the initial stage of nanoparticle synthesis (Fig. 10a). After approximately $1 \mathrm{~h}$, a second peak starts to appear in the spectrum of the colloid created with PEI, confirming presence of silver nanoparticles (Fig. 10b). Its intensity increased considerably with prolonging synthesis time. After about $5 \mathrm{~h}$, the peak at $310 \mathrm{~nm}$ entirely disappeared, indicating that the intermediate forms of silver had transformed into metallic nanoparticles (Mercado et al. 2002).

To confirm the above conclusions and observations, electrochemical tests were conducted on NMMO solutions containing only silver nitrate or silver nitrate 
Fig. 8 Effect of polymeric stabilizer on reduction and stabilization of nanoparticles: a UV-Vis spectrum; b, c HRTEM images of silver in NMMO samples at 1 week after synthesis: b sample with PEI; c sample without PEI (a)

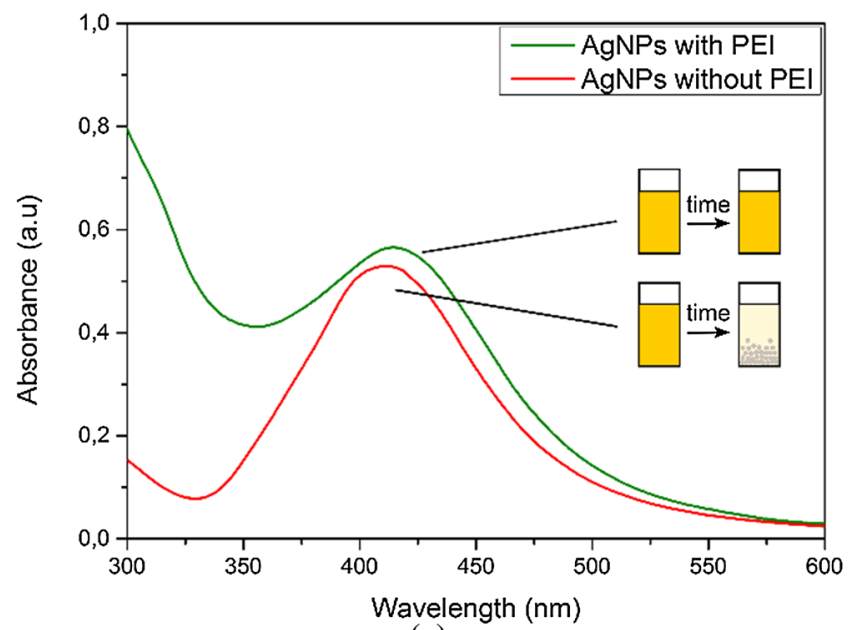

(b)

(c)

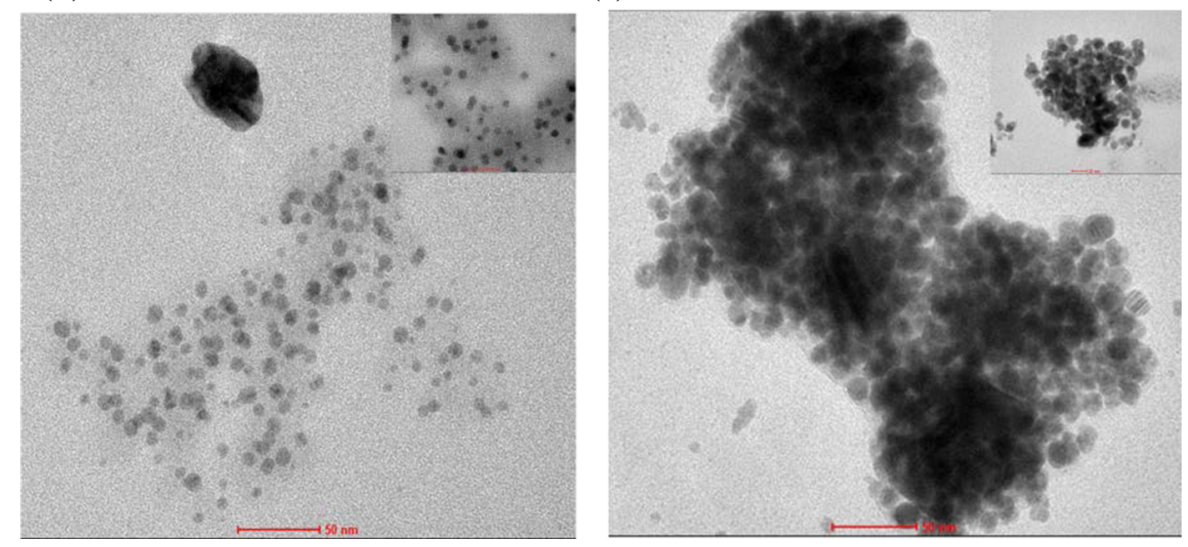

and polyethylenimine (Fig. 11). The tests were carried out in a two-electrode system, measuring the changes in the potential of a silver-ion-selective electrode. According to the Nernst equation, the reference electrode potential depends on the concentration of silver ions (4) as follows:

$E=E^{0}+\frac{R T}{n F} \ln \left(\mathrm{Ag}^{+}\right)$,

where $E$ is the electrode potential, $E^{0}$ is the standard electrode potential, $R$ is the gas constant with value of $8.314 \mathrm{~J} \mathrm{~K}^{-1} \mathrm{~mol}^{-1}, T$ is temperature $(\mathrm{K}), n$ is the number of electrons exchanged in the reaction, and $F$ is the Faraday constant with value of 96,485 $\mathrm{C} \mathrm{mol}^{-1}$.

A decrease of the reference electrode potential was observed after adding silver nitrate to the NMMO or NMMO with PEI solution. In the initial stage, in the solution without PEI, the potential remained at a constant level due to the fact that the reaction was very slow (Fig. 9c). In the case of synthesis in NMMO with PEI solution, there was a slight decrease in the potential, symptomatic of slow reduction of silver ions according to reactions (1-3). Afterwards, the electrode potential settled at a stable level of $250 \mathrm{mV}$. These results are consistent with the UVVis test results. On the basis of both measurements, it can be concluded that complete reduction of silver ions occurred within approximately $24 \mathrm{~h}$ in the solution containing PEI, whereas in absence of PEI, no silver ion reduction occurred in the solution within the first $50 \mathrm{~h}$.

\section{Mechanism of silver nanoparticle synthesis in NMMO}

To describe the entire mechanism of nanoparticle synthesis, it is essential, in the first place, to determine the agent responsible for reducing the silver ions. It is known that reduction of silver ions may be triggered by ultraviolet electromagnetic radiation, elevated 

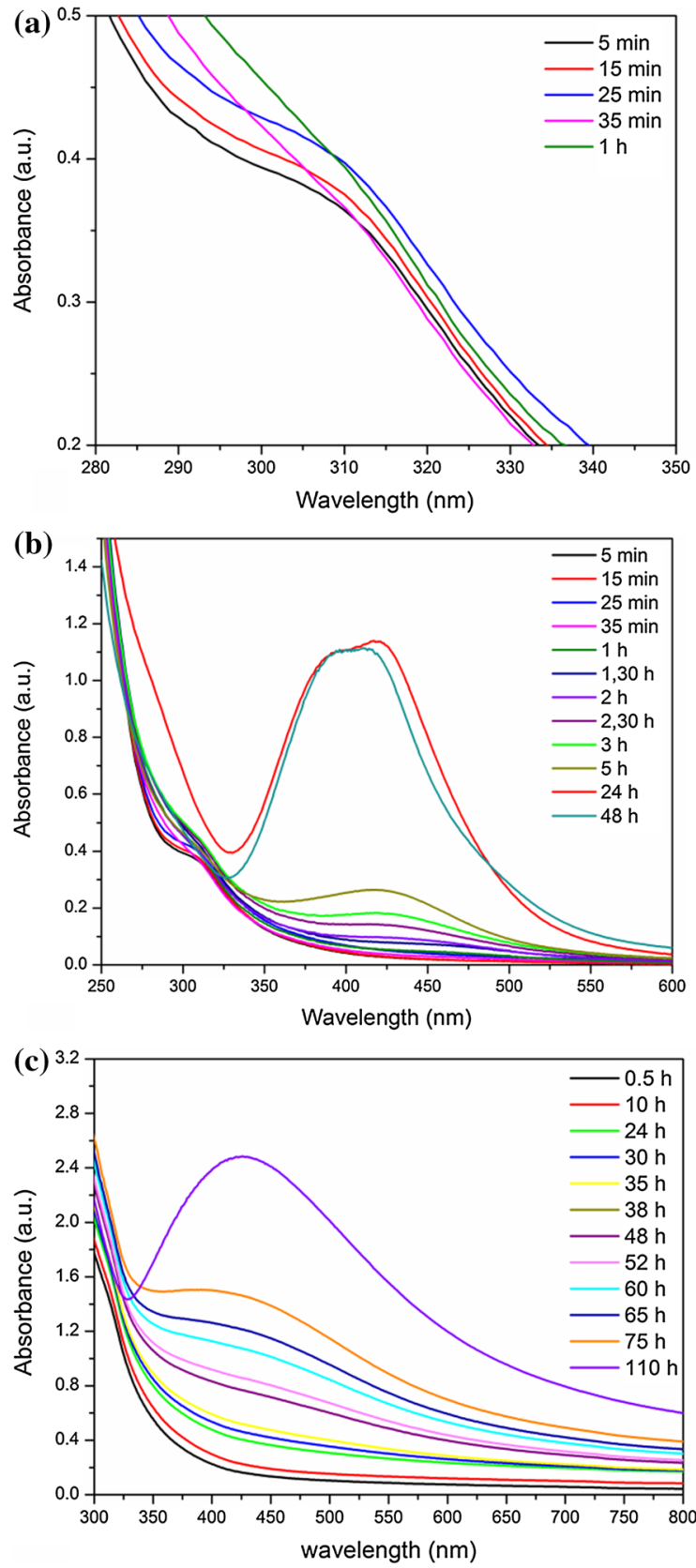

Fig. 9 Changes in UV-Vis spectrum over time for silver colloids with PEI: $\mathbf{a}$ in initial stage of reaction; $\mathbf{b}$ during the whole reaction time. c Changes in UV-Vis spectrum over time for silver colloid without polymer

temperature, or a reducer. The reduction of silver ions in solution of $\mathrm{N}$-methylmorpholine $\mathrm{N}$-oxide is a typical oxidation-reduction process. The solvent is water containing $50 \% \mathrm{NMMO}$ by weight plus polyethylenimine as stabilizing agent. In such solutions, silver ion reduction is also triggered without a stabilizing agent. To define the mechanism of $\mathrm{Ag}$ nanoparticle synthesis, it is vital to determine which substance in the solution acts as a $\mathrm{Ag}^{+}$ion reducer. It is common knowledge that NMMO is a very strong oxidant (Rosenau et al. 2001).

In the presented research, all reactions were conducted in the dark (with vessels wrapped in tin foil), so electromagnetic radiation could not be a reducing agent. Elevated temperature was also excluded, because the reduction process in NMMO solution occurred at both ambient and elevated temperature $\left(70{ }^{\circ} \mathrm{C}\right)$. Therefore, the reducing agent must be a substance found in the solution. In nanoparticle synthesis, a stabilizing polymer may have a double function, acting as both stabilizer and reducing agent (Note et al. 2006). However, the results above show that polyethylenimine does not act as a reducer here, since silver ion reduction also occurred in NMMO solution without polyethylenimine.

As silver ion reduction in NMMO is a redox reaction, and factors such as temperature, light, and presence of polyethylenimine can be excluded, we investigated further to identify the reducing agent. The solution in which the silver nanoparticles were synthesized contained NMMO molecules, water, polyethylenimine, hydroxyl ions, nitrate ions, and silver ions undergoing reduction. Since solution $\mathrm{pH}$ is an important parameter influencing chemical reactions, changes in acidity were monitored during the synthesis (Lee et al. 2004). The solution acidity is a significant parameter for synthesis of nanoparticles, particularly due to the fact that the shape of polymer molecules depends not only on the structure of the polymer chain but also on the solution $\mathrm{pH}$. It has been reported that, at high $\mathrm{pH}$, PEI deprotonation occurs and its chain begins to roll up. At appropriate $\mathrm{pH}$ and PEI chain length, agglomeration of nanoparticles does not occur (Yuan and Li 2010).

The acidity of the aqueous NMMO solution (50\% by weight) was approximately 9.37. After adding silver nitrate to the solution, there was a sharp decline in $\mathrm{pH}$ to approximately 9.3 (Fig. 12a), due to dissociation and hydrolysis of dissolved silver nitrate.

The $\mathrm{pH}$ not only influences the behavior of the PEI chains but also affects the NMMO. Aqueous solution of NMMO is alkaline in nature, being a strong oxidant, and very labile in acidic environment. With decreasing $\mathrm{pH}$, the protonation of NMMO significantly increases, 
Fig. 10 Chemical scheme of silver nanoparticle synthesis: a synthesis of intermediate forms of silver, $\mathbf{b}$ synthesis of $\mathrm{Ag}$ nanoparticles

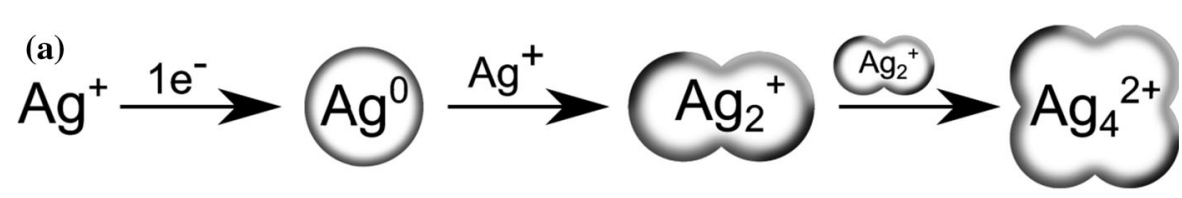

(b)

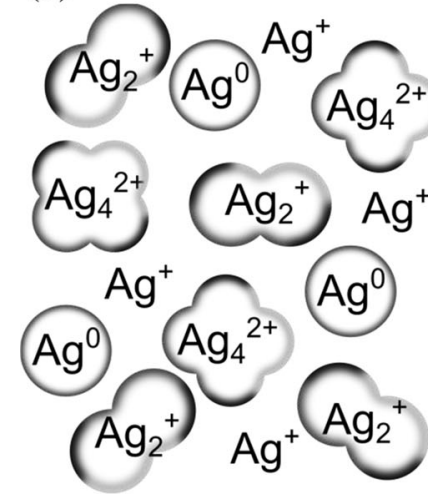

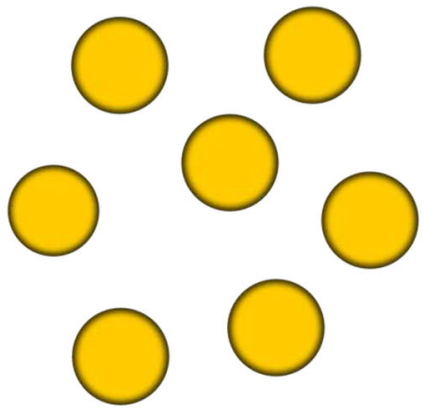

silver nanoparticles
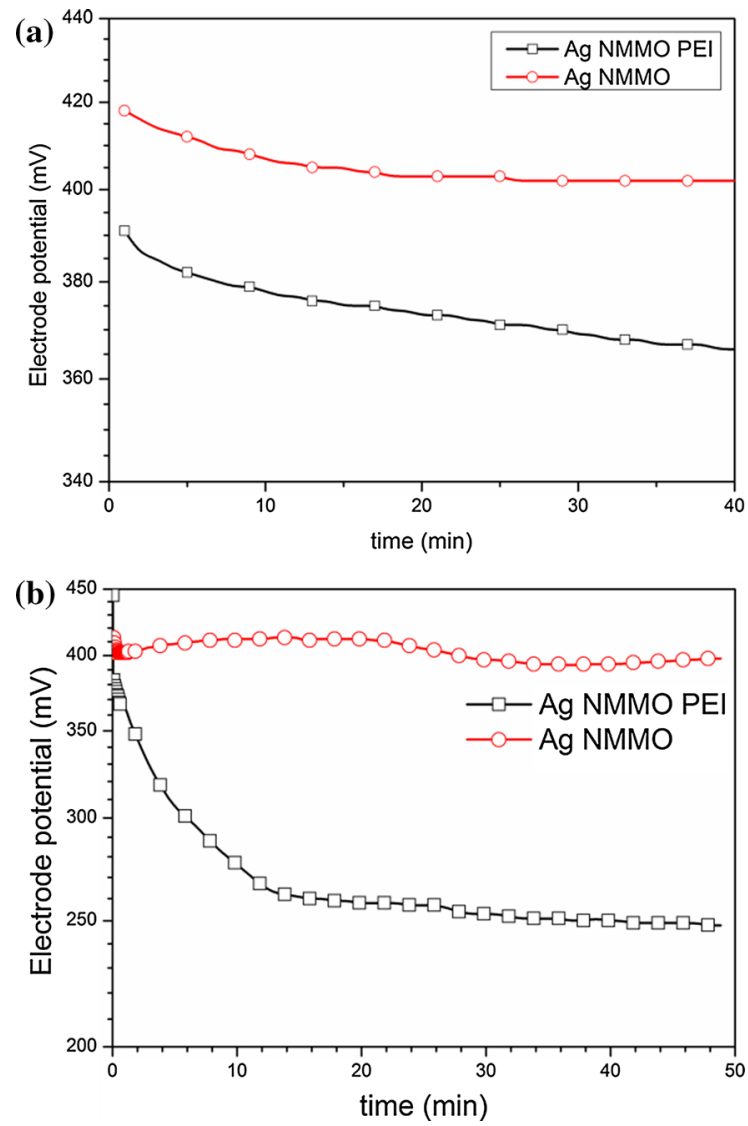

Fig. 11 Potentiometric test of silver nanoparticle solutions in NMMO with silver-ion-selective electrode: $\mathbf{a}$ in first stage of synthesis, $\mathbf{b}$ during entire course of synthesis leading to decomposition of NMMO into $\mathrm{N}$-methylmorpholine (NMM) and morpholine (M), because the protonated form of NMMO is very labile (Jung et al. 1996). Although commercially available NMMO contains insignificant amounts of NMM and $\mathrm{M}$, it further decomposes in presence of metals, negatively affecting spinning solution preparation. Therefore, elevated $\mathrm{pH}$ due to addition of PEI leads to stabilization of NMMO rather than its decomposition. The conductance of the colloids was tested during the 4 days of synthesis. In the case of synthesis conducted in presence of polyethylenimine, the solution conductance decreased in the first $24 \mathrm{~h}$, then settled at a stable level of about $100 \mu \mathrm{S} / \mathrm{cm}$ (Fig. 13). This decrease in conductance was caused by silver ion reduction and synthesis of nanoparticles. The settling of the conductance at a stable level, similar to the conductance of pure NMMO, indicates that complete reduction of $\mathrm{Ag}^{+}$ions had taken place. These results correspond to those of UV-Vis spectroscopy (Fig. 9) and the silver ion concentration measurements (Fig. 11), in which the potential also stabilized after $24 \mathrm{~h}$. In the case of synthesis conducted without PEI, the solution conductance decreased continuously despite the fact that, in the initial stage, the number of $\mathrm{Ag}^{+}$ions did not decrease in the chemical composition, as confirmed by the UV-Vis test results (Fig. 9c). The decrease in conductance may be connected with changes in NMMO triggered by metal ions (Rosenau et al. 2001). As mentioned above, 

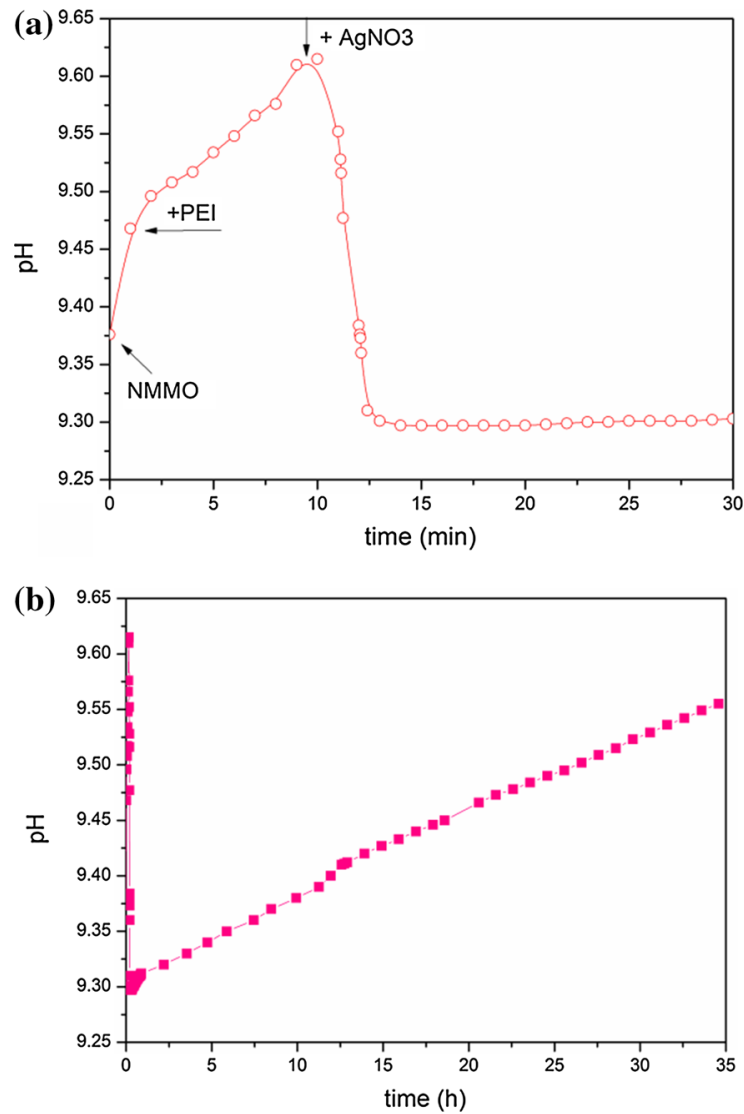

Fig. 12 Results of $\mathrm{pH}$ tests conducted during silver nanoparticle synthesis: a in first stage of synthesis, $\mathbf{b}$ during entire course of synthesis

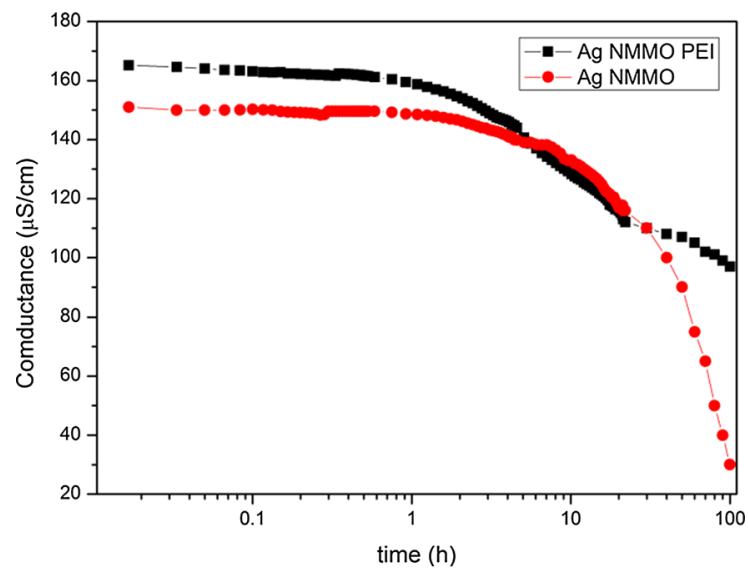

Fig. 13 Conductance tests of silver colloid in NMMO

NMMO is a labile compound, and in reaction with cellulose and/or heavy metals, decomposes to $\mathrm{N}$ methylmorpholine, morpholine, carbon dioxide, and water as main products (Taeger et al. 1985). During such degradation, highly labile intermediate products such as methyl radical morpholinium, and $\mathrm{N}$ (methylo)cation morpholinium are also created (Rosenau et al. 2001). It is commonly believed that, in the cellulose/NMMO system, degradation of NMMO is most effectively prevented by alkaline hydroxides and antioxidant stabilization ( $\mathrm{NaOH}$ or $\mathrm{PG}$, propyl gallate). Substances containing functional groups or surface-active materials can additionally trigger the degradation process (Wendler et al. 2005). Each of these additional characteristics, i.e., $\mathrm{pH}$ value, presence of functional groups $\left(-\mathrm{COOH},-\mathrm{NH}_{2}\right)$, surface structure, particle size, etc., could lead to potential interactions with main components of the NMMO/cellulose solution. Activation of the highly labile structure of the NMMO molecule is triggered by protonation, creating complexes with metals or $O$ alkylation. Loosening of the NMMO ring structure leads to creation of resonance-controlled nitroxyl radicals and permanent ring-degradation products. Our test results confirmed that polyethylenimine not only stabilized nanoparticles by preventing their agglomeration but also prevented NMMO degradation by avoiding its contact with the metal surface.

The mixture in which the silver nanoparticle synthesis was conducted contained $\mathrm{Ag}^{+}, \mathrm{NO}_{3}^{-}$, and $\mathrm{OH}^{-}$ions, polyethylenimine, water molecules, and $N$ methylmorpholine $N$-oxide. It should be concluded that the silver, nitrogen, and hydrogen atoms are at their highest oxidation level, while oxygen atoms are at their lowest. This means that, in the solution, there are three substances which may act as an oxidizer: $\mathrm{NMMO}$ and $\mathrm{Ag}^{+}$and $\mathrm{NO}_{3}^{-}$ions. The fact that the solution is alkaline (Fig. 12) whereas nitrate ion reduction occurs in acidic solution indicates that they will not participate in the studied reaction. The standard electrochemical potential for oxidation of hydroxyl ions (5) is $0.88 \mathrm{~V}$, significantly lower than the NMMO potential $(1.47 \mathrm{~V})$. As NMMO is a strong oxidant and has higher potential in solution, reaction (6) will occur first:

$E=0.88 \mathrm{~V} \quad 3 \mathrm{OH}^{-} \rightarrow \mathrm{HO}_{2}^{-}+\mathrm{H}_{2} \mathrm{O}+2 \mathrm{e}^{-}$

$$
\begin{aligned}
& E=1.47 \mathrm{~V} \\
& \mathrm{NMMO}+2 \mathrm{OH}^{-} \rightarrow \mathrm{NMM}+\mathrm{H}_{2} \mathrm{O}+\mathrm{HO}_{2}^{-}
\end{aligned}
$$

It is reported that, in the reaction of metal ions with $\mathrm{NMMO}$, the ions act as a reducer and NMMO as an 
oxidant. However, these reactions do not occur when the metal ions are at their highest oxidation level, as is the case for silver here (Ferris et al. 1967). Perhydroxyl ions $\left(\mathrm{HO}_{2}^{-}\right)$created as a result of reaction (6) oxidize according to reaction (7), whose potential $(-0.76 \mathrm{~V})$ is lower than that of silver ions $(0.799 \mathrm{~V}, 8)$. Hence, the created perhydroxyl ions may act as the silver ion $\left(\mathrm{Ag}^{+}\right)$reducer according to the final reaction (9).

$$
E=-0.76 \mathrm{~V} \quad \mathrm{HO}_{2}^{-}+\mathrm{OH}^{-} \rightarrow \mathrm{H}_{2} \mathrm{O}+\mathrm{O}_{2}+2 \mathrm{e}^{-}
$$

$$
E=0.799 \mathrm{~V} \quad \mathrm{Ag}^{+}+\mathrm{e}^{-} \rightarrow \mathrm{Ag}^{0}
$$

$$
2 \mathrm{Ag}^{+}+\mathrm{HO}_{2}^{-}+\mathrm{OH}^{-} \rightarrow 2 \mathrm{Ag}^{0}+\mathrm{H}_{2} \mathrm{O}+\mathrm{O}_{2}
$$

On the basis of the above test results and analysis of literature data, the authors conclude that perhydroxyl ions act as a reducer in silver nanoparticle synthesis in
NMMO. Moreover, $\mathrm{pH}$ plays a significant role in this process, as appropriately high $\mathrm{pH}$ accelerates such synthesis. This explains the influence of polyethylenimine on the synthesis. Apart from stabilizing already formed nanoparticles, it also accelerates the reaction due to the increased solution $\mathrm{pH}$, i.e., higher number of $\mathrm{OH}^{-}$ions, which accelerates reaction (6) and thereby $\mathrm{Ag}^{+}$reduction according to reaction (9).

\section{Characteristics of fibers}

\section{Microstructure of fibers}

SEM analysis of the cellulose fiber microstructure revealed a smooth surface (Fig. 14), even after modification. Such maintenance of the fiber smoothness was possible as the whole volume of the fiber was doped rather than just the surface. The appearance of
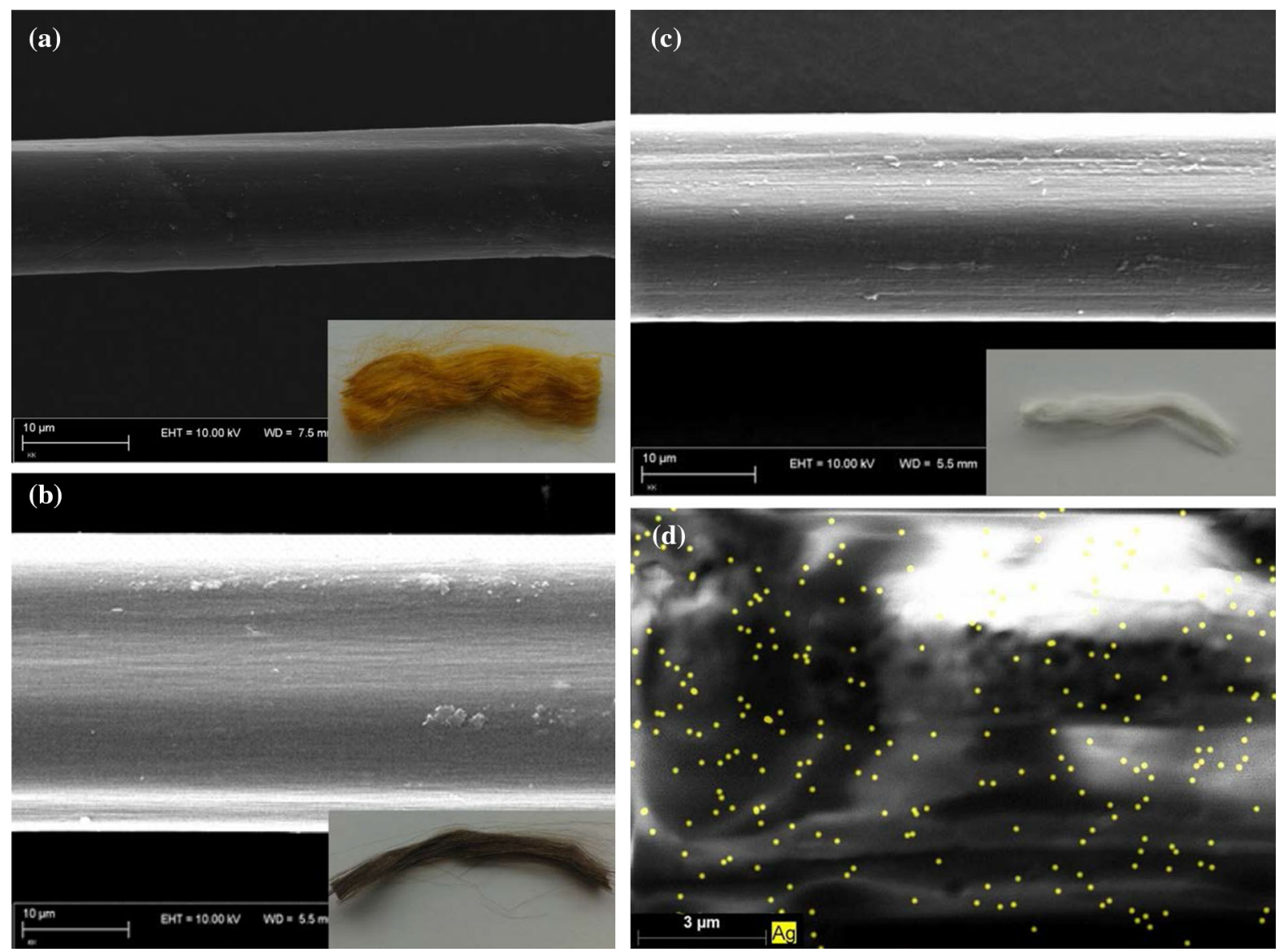

Fig. 14 SEM images (with inset photograph) of cellulose fibers a doped with silver nanoparticles obtained using PEI, b and without PEI, $\mathbf{c}$ and in pure state. d Analysis of dispersion of silver nanoparticles in fiber obtained using Ag with PEI 
the doped fibers was visibly different, changing color after doping. The pure cellulose fibers (Fig. 14c) were white, whereas the fibers with silver nanoparticles, depending on the kind of stabilizing polymer applied, were yellowish orange in color (Fig. 14a), or dark brown in case of synthesis without stabilizer (Fig. 14b). The color change in the fibers is due to the effect of surface plasmon resonance in the silver nanoparticles in the doped fibers. Fibers containing silver created without polyethylenimine addition were dark brown, because the size of the silver particles did not exceed $200 \mathrm{~nm}$. Lack of stabilizer led to creation of much larger particles in the cellulose matrix. Additionally, analysis of the silver dispersion in the fibers (Fig. 14d) showed that the silver nanoparticles were uniformly dispersed throughout the entire fiber volume.

\section{Mechanical tests}

Tests of mechanical properties revealed that doping the fibers with silver nanoparticles led to a significant improvement of their mechanical properties (Table 1). Composite fibers could bear much higher loads and showed higher Young's modulus. The size and uniform dispersion of the nanoparticles in the volume of the composite fibers led to the increased Young's modulus, an effect commonly known as dispersion strengthening of composite materials. The endurance of cellulose fibers doped with silver nanoparticles obtained without polymeric stabilizer was $24.59 \mathrm{cN} / \mathrm{tex}$, similar to previously achieved results falling in the range of $22.00-24.27 \mathrm{cN} / \mathrm{tex}$ (Smiechowicz et al. 2011). Fibers containing stabilized silver nanoparticles in their volume were characterized by higher endurance $(29.73 \mathrm{cN} /$ tex $)$ in comparison with nondoped fibers $(28.42 \mathrm{cN} / \mathrm{tex})$. The higher mechanical endurance of these fibers is due to the small volume and good dispersion of the admixture in the fibers. It may also be due to improved fiber quality, because, as previously reported, PEI also acts as an NMMO stabilizer, preventing its degradation during fiber synthesis. These results confirm the need to apply additives to stabilize the size of nanoparticles synthesized in situ.

\section{Influence of cellulose on silver reduction}

We first tested the formation of nanoparticles in NMMO solution. This is a very interesting research problem, because this process occurs without use of standard reducing agents such as ascorbic acid, but in presence of NMMO, a strong oxidant. The analysis above demonstrates that redox processes take place in the $\mathrm{AgNO}_{3}-\mathrm{NMMO}$ system, leading to formation of perhydroxyl ions, which act as a reducer of silver ions. Such conclusions are novel, and verified based on a series of tests. This finding greatly contributes to the scientific achievements in this field, and may can help understand a number of phenomena that occur during nanoparticle doping processes.

We next synthesized silver nanoparticles in a system for fiber preparation. Cellulose dissolution was carried out in a closed reactor at elevated temperature and pressure. Under such conditions, it is not possible to control the progress of silver ion reduction. To examine indirectly the impact of cellulose on the mechanism of the observed reactions, we prepared fibers with and without PEI, considering the possibility that cellulose might stabilize the nanoparticles. These experiments showed that the resulting cellulose material failed to meet expectations, having dark-brown colour typical of microparticles (Fig. 14b) and poorer mechanical strength (Table 1), showing that it is indispensable to apply a stabilizer such as PEI. These results suggest that cellulose did not significantly affect the silver nanoparticle synthesis, in terms of either reduction or their stabilization. Additionally,

Table 1 Mechanical properties of cellulose fibers

\begin{tabular}{llllc}
\hline Fiber type & $\begin{array}{l}\text { Linear mass density } \\
(\text { tex })\end{array}$ & $\begin{array}{l}\text { Breaking strength } \\
(\mathrm{cN})\end{array}$ & $\begin{array}{l}\text { Young's modulus } \\
(\mathrm{cN} / \text { tex })\end{array}$ & $\begin{array}{l}\text { Tensile strength } \\
(\mathrm{cN} / \text { tex })\end{array}$ \\
\hline Cellulose reference fibers & 0.360 & $10.2 \pm 2.2$ & $1532 \pm 407$ & $28.4 \pm 6.0$ \\
Cellulose + AgNPs + PEI & 0.512 & $15.2 \pm 2.9$ & $1585 \pm 342$ & $29.7 \pm 5.7$ \\
Cellulose + AgNPs & 0.697 & $17.1 \pm 4.4$ & $1276 \pm 368$ & $24.6 \pm 6.2$ \\
\hline
\end{tabular}


Emam and El-Bisi (2014); Emam et al. (2014) presented a method for synthesis of silver nanoparticles using different types of cellulosic materials. It was demonstrated there that $\mathrm{Ag}^{+}$ions are reduced to AgNPs, simultaneously oxidizing cellulose. Alcoholic and aldehydic groups in cellulose change to an oxidized form, e.g., carboxylic groups. These studies show that reduction of $\mathrm{Ag}^{+}$ions affects Lyocell fibers, because they are spun using NMMO, a strong oxidant. These studies confirm the hypothesis that cellulose has an insignificant effect on the investigated reduction reaction of $\mathrm{Ag}^{+}$ions. During fiber production, when silver ions are reduced, antioxidant and PEI are also added to the system, preventing cellulose degradation. Therefore, the elaboration of the exact mechanism of Ag nanoparticle synthesis in NMMO will help understand the phenomena taking place during in situ synthesis of nanoparticles in spinning solution.

\section{Conclusions}

This study shows that, during synthesis of silver nanoparticles in NMMO solution, the best stabilizer is polyethylenimine, especially with medium or low molecular weight, while no nanoparticles are synthesized when applying other stabilizers. The reduction process should be conducted in the dark to avoid fast triggering of silver reduction by light, which would prevent stabilization of the nanoparticles by the polymer. As such colloids may be heated, it is possible to use them during production of spinning solution, which is also heated to dissolve cellulose in NMMO.

Based on the electrochemical potential of all ions in solution, a mechanism for the nanoparticle synthesis is suggested. Perhydroxyl ions, created as a result of a number of sequential reactions occurring in NMMO, may act as a reducer of silver ions to metallic nanoparticles. Their standard oxidation-reduction potential is significantly lower than the standard potential for silver ion reduction. The role of polyethylenimine in the reaction was also investigated. In the tested silver reduction reaction, polyethylenimine acts as a stabilizing agent with a threefold role: accelerating reduction of silver ions to metallic nanoparticles by changing the $\mathrm{pH}$ of the solution, while also preventing NMMO degradation during the synthesis (Wendler et al. 2008) as well as agglomeration of silver nanoparticles. On the basis of the developed method for silver nanoparticle synthesis in NMMO, a cellulose spinning solution with nanoparticles was prepared, resulting in nanocomposite fibers doped with silver nanoparticles, which showed improved mechanical properties compared with unmodified fibers.

Acknowledgments This work was financed by a fund for science in the years 2013-2017 as a research project within the "Diamond Grant" program (no. DI2012 005142) and by the National Science Centre (decision number DEC-2012/07/B/ ST8/03698).

Open Access This article is distributed under the terms of the Creative Commons Attribution 4.0 International License (http:// creativecommons.org/licenses/by/4.0/), which permits unrestricted use, distribution, and reproduction in any medium, provided you give appropriate credit to the original author(s) and the source, provide a link to the Creative Commons license, and indicate if changes were made.

\section{References}

Allen M, Alastalo A, Suhonen M, Mattila T, Leppaniemi J, Seppa H (2011) Contactless electrical sintering of silver nanoparticles on flexible substrates. IEEE Trans Microw Theory Tech 59:1419-1429

Courrol LC, Oliveira Silva FR, Gomez L (2007) A simple method to synthesize silver nanoparticles by photo-reduction. Colloids Surf A 305:54-57

Emam HE, Ahmed HB (2016) Polysaccharides templates for assembly of nanosilver. Carbohydr Polym 135:300-307

Emam HE, El-Bisi MK (2014) Merely Ag nanoparticles using different cellulose fibers as removable reductant. Cellulose 21:4219-4230

Emam HE, Zahran MK (2015) $\mathrm{Ag}^{0}$ nanoparticles containing cotton fabric: synthesis, characterization, color data and antibacterial action. Int J Biol Macromol 75:106-114

Emam HE, Manian AP, Siroka B, Duelli H, Redl B, Pipal A, Bechtold T (2013) Treatments to impart antimicrobial activity to clothing and household cellulosic-textiles-why "nano"-silver? J Clean Prod 39:17-23

Emam HE, Mowafi S, Mashaly HM, Rehan M (2014) Production of antibacterial colored viscose fibers using in situ prepared spherical Ag nanoparticles. Carbohydr Polym 110:148-155

Emam HE, Rehan M, Mashaly HM, Ahmed HB (2016) Large scaled strategy for natural/synthetic fabrics functionalization via immediate assembly of AgNPs. Dyes Pigment 133:173-183

Ferris JP, Gerwe RD, Gapski GR (1967) Iron-catalyzed dealkylation of trimethylamine oxide. J Am Chem Soc 89:5269-5275

Jung GY, Kim TH, Kim HB (1996) Separation of morpholine, $N$-metylmorpholine and $N$-methylmorpholine- $N$-oxide by indirect UV absorption capillary electrophoresis. Anal Sci 12:367-369 
Karbownik I, Kulpinski P, Czarnecki P, Rubacha M, Peczek B, Teterycz H, Rac O, Oles D, Fiedot M, Halek P, Halek G, Wisniewski K, Suchorska P (2012) Method for modification of synthetic fibers, especially cellulose. Patent 220020

Karbownik I, Rac O, Fiedot M, Suchorska-Wozniak P, Teterycz H (2015) In situ preparation of silver-polyacrylonitrile nanocomposite fibres. Eur Polym J 69:385-395

Kholoud MM, El-Nour A, Eftaiha A, Al-Warthan A, Ammar RAA (2010) Synthesis and applications of silver nanoparticles. Arab J Chem 3:135-140

Kim CJ, Khan W, Kim DH, Cho KS, Park SY (2011) Graphene oxide/cellulose composite using NMMO monohydrate. Carbohydr Polym 86:903-909

Lee GJ, Shin SI, Kim YC, Oh SG (2004) Preparation of silver nanorods through the control of temperature and $\mathrm{pH}$ of reaction medium. Mater Chem Phys 84:197-204

Lee HJ, Lee SG, Oh EJ, Chung HY, Han SI, Kim EJ, Seo SY, Ghim HD, Yeum JH, Choi JH (2011) Antimicrobial polyethyleneimine-silver nanoparticles in a stable colloidal. Dispers Colloids Surf B 88:505-511

Mercado LA, Castro W, Vicuna E, Briano JG, Ishikawa Y, Irizarry R, Sola L, Castro ME (2002) Real time kinetic measurements of silver nanocluster growth. In: 2002 international conference on computational nanoscience and nanotechnology-ICCN, pp 439-442

Mie G (1908) Contribution to the optics of turbid media particularly of colloidal metal solutions. Ann Phys 25:377-445

Mikami T, Takayasu Y, Watanabe J, Hirasawa I (2011) Influence of polyethyleneimine addition on crystal size distribution of Au nanocrystals. Chem Eng Technol 34:583-586

Note C, Kosmella S, Koetz J (2006) Poly(ethyleneimine) as reducing and stabilizing agent for the formation of gold nanoparticles in w/o microemulsions. Colloids Surf A 290:150-156

Rosenau T, Potthast A, Sixth H, Kosma P (2001) The chemistry of side reactions and byproduct formation in the system NMMO/cellulose (Lyocell process). Prog Polym Sci 26:1763-1837
Sato-Berru R, Redon R, Vazquez-Olmos A, Singer JM (2009) Silver nanoparticles synthesized by direct photoreduction of metal salts. Application in surface-enhanced Raman spectroscopy. J Raman Spectrosc 40:376-380

Siro I, Plackett D (2010) Microfibrillated cellulose and new nanocomposite materials: a review. Cellulose 17:459-494

Smiechowicz E, Kulpinski P, Niekraszewicz B, Bacciarelli A (2011) Cellulose fibers modified with silver nanoparticles. Cellulose 18:975-985

Starch M, El-Rafie MH, Ahmed HB, Zahran MK (2014) Facile precursor for synthesis of silver nanoparticles using alkalitreated maize starch. Int Sch Res Notices, Article ID 702396

Taeger E, Franz H, Mertel H, Schleicher H, Lang H, Lukanoff B (1985) Formeln Fasern Fertigware 4:14-22

Wendler F, Kolbe A, Meister F, Heinze T (2005) Thermostability of lyocell dopes modified with surface-active additives. Macromol Mater Eng 290:826-832

Wendler F, Meister F, Montigny R, Wagener M (2007) A new antimicrobial ALCERU fibre with silver nanoparticles. Fibres Text East Eur 15:64-65

Wendler F, Konkin A, Heinze T (2008) Studies on the stabilization of modified lyocell solutions. Macromol Symp 262:72-84

Yuan W, Li CM (2010) Exponentially growing layer-by-layer assembly to fabricate $\mathrm{pH}$-responsive hierarchical nanoporous polymeric film and its superior controlled release performance. Chem Commun 46:9161-9163

Zabetakis D, Dinderman M, Schoen P (2005) Metal-coated cellulose fibers for use in composites applicable to microwave technology. Adv Mater 17:734-738

Zahran MK, Ahmed HB, El-Rafie MH (2014) Alginate mediate for synthesis controllable sized AgNPs. Carbohydr Polym 111:971-978

Zhang W, Qiao X, Chen J (2007) Synthesis of silver nanoparticles-effects of concerned parameters in water/oil microemulsion. Mater Sci Eng A 142:1-15 